\title{
La enseñanza de la entomología mediante sellos postales como recurso didáctico
}

\author{
Teaching Entomology with postage stamps as didactic resource
}

\author{
Paola Turienzo ${ }^{1}$
}

\section{RESUMEN}

En los últimos años, se comenzó a hipotetizar acerca de la filatelia como recurso didáctico de diferentes disciplinas, enumerando varias ventajas por las que se debería utilizar en la enseñanza. Se dan a conocer los trabajos vinculados con sellos de insectos y sobre educación de las ciencias con esta metodología. Con base en experiencias obtenidas en aula, utilizando sellos postales, se pretende argumentar su uso en la enseñanza de la entomología en nivel superior.

Palabras claves: sellos postales, filatelia, entomología, enseñanza y aprendizaje

\begin{abstract}
In lasts years, the philately began to be use as hypothetical resource in the teaching of different science, for many advantages in classroom. Investigation dealing with insects stamps and with the useful importance in science education with this methodology are given. With classroom experience in the use of stamps, this paper pretend to argue about the importance to put in practice the teaching of entomology in university level.

Keywords: postage stamps, philately, entomology, teaching and learning
\end{abstract}

\section{Introducción}

La filatelia consiste en el interés por coleccionar y clasificar sellos, sobres y documentos postales de diversa naturaleza. A su vez se divide en filatelia tradicional o clásica y filatelia temática. La tradicional o clásica organiza los sellos de un país por orden cronológico y puede reunirse por épocas, emisiones y estudios específicos. La colección temática reúne sellos postales, ya sea por la imagen o por el motivo de la emisión (Correos de Chile, 2013).

Podemos decir que existen distintos intereses aun en el mundo de las emisiones postales, ya que el científico exigiría la difusión pormenorizada y sistemática de las especies autóctonas que estudia, en un plan prolongado en el tiempo, en tanto que la emisión postal se limita a la esporádica impresión de sellos que priorizan los ejemplares más vistosos de cada familia. Aun entre los filatelistas, la manera de encarar la clasificación de los sellos es sustancialmente diversa: mientras algunos siguen la estructura de la ciencia (taxonomía/sistemática), otros lo hacen por área de difusión o cronológicamente por países de emisión de la serie (cabe aclarar que las estampillas temáticas rara vez se emiten individualmente, sino por serie de valores) (Turienzo \& Alves Carneiro, 2014).

Las plantas (incluidos los árboles, flores y frutos por separado), hongos, invertebrados de diversos grupos, las aves, mamíferos, peces, anfibios y reptiles, representan una gran área temática que se halla comprendida en lo que denominamos filatelia de la historia natural. También pueden incluirse los fósiles de diversos grupos taxonómicos. A la relación insectoestampilla se la conoce como entomofilatelia.

1 Universidad Nacional de Cuyo. Facultad de Ciencias Agrarias. Chacras de Coria. Luján de Cuyo. Mendoza. Argentina.
* Autor por correspondencia: pturienzo@fca.uncu.edu.ar

Fecha de recepción: 11 diciembre, 2017.

Fecha de aceptación: 20 julio, 2018.

DOI: http://dx.doi.org/10.4067/S0718-34292018005001701. Publicado en línea: 8-enero-2019. 
La filatelia puede ser un poderoso medio de divulgación científica para sensibilizar a la sociedad sobre la importancia de las investigaciones científicas (Penereiro \& Lombardo Ferreira, 2010, 2011). A su vez, como recurso didáctico presenta múltiples ventajas, además de resultar novedoso para los alumnos (Salazar \& Turienzo, 2018). Con el estudio de los sellos no solo se aprende del ejemplar ilustrado, sino también de la importancia y su contexto (para que un país lo represente en su correo postal y la importancia cultural que ese ejemplar supone). A veces, hay países que representan ejemplares en sus sellos y su distribución no es coincidente con su territorio. Este tipo de situaciones lleva al estudio de la distribución natural de las especies y al estudio de la geografía del planeta, no solo en cuanto al paisaje, sino también a la historia de los países. Para ejemplificar, los sellos que presentan como país a Československo (cuando era Checoslovaquia) son, a nivel territorial, muy próximos a lo que luego se denomina Czech Republic, cuando se separó de Slovakia (para ser República Checa). Nombres diferentes según las épocas, donde es factible que sigan distribuyéndose las mismas especies. Otro tema son los territorios altamente complejos a nivel político como las bases antárticas. Con la filatelia se pueden conocer especies que quizás nunca podamos visitar por su lejanía o por estar próximas a la extinción. También se pueden estudiar fósiles y tiempos geológicos muy diversos, recreando los ejemplares (Turienzo \& Alves Carneiro, 2017).

Dado que los sellos postales son una herramienta poco explorada para los análisis científicos (Penereiro, 1997), el objetivo de este trabajo es, mostrar, cómo diversos trabajos de divulgación científica o trabajos científicos, pueden ayudar como recurso didáctico para readaptar una investigación didáctica, en un contexto entomológico.

Cabe destacar a su vez que, si bien los sellos han sido ampliamente utilizados en la enseñanza de la ciencia, sobre todo de la matemática, ingeniería, astronomía y química (Penereiro, 1997, Penereiro \& Lombardo Ferreira, 2010, 2011, Martínez-Reina \& Amado-González, 2013, 2016), no ha sido así en la enseñanza de la biodiversidad (Madero et al., 2013, Turienzo \& Alves Carneiro, 2017, Salazar \& Turienzo, 2018).

\section{Materiales y método}

Para el siguiente trabajo se utiliza de referencia la colección temática de la autora (flora y fauna mundial, hongos, minerales, fósiles, cavernas y mapas). Esta colección está clasificada por países y dentro de estos por taxa (respecto de la representación de seres vivos). Consta de una clasificación etiquetada por colores, donde se indican con una combinación de tres de ellos: 1) Número de sello de la taxa en cuestión 2) Número de sello de la colección general y 3) Número de catálogo mundial Yvert \& Tellier, sumado al nombre científico en la medida de lo posible (con su correspondiente familia).

Para la temática particular de sellos entomológicos se contaba con 499 sellos (al 5 de diciembre de 2017), de los cuales 56,7 \% correspondían a Lepidoptera, $19,8 \%$ a Coleoptera y 7,4 \% a Hymenoptera. Ejemplo de algunos sellos por taxa en Figura 3, 4, 5, 6 y 7.

Cabe destacar que el material filatélico ha demandado mucho tiempo de coleccionismo, lo cual constituye un acervo de inestimable valor personal, monetario y científico, como bien lo expresaran en su trabajo Penereiro \& Lombardo Ferreira (2010).

Desde hace un tiempo se vienen proponiendo diferentes usos de los sellos postales, en diferentes niveles educativos, como una herramienta divertida y de investigación concreta (Turienzo \& Salazar, 2018, Turienzo \& Barchiesi, en prep.).

En esta ocasión concreta, la propuesta se realiza con base en la enseñanza de la entomología.

\section{Resultados y discusión}

Si comparamos la colección de la autora (al 2017) con la de los órdenes de insectos en estampillas mundiales a 1990 (modificado de Mendoza Ramírez et al., 2006), observamos que las proporciones se mantienen (Tabla 1). 


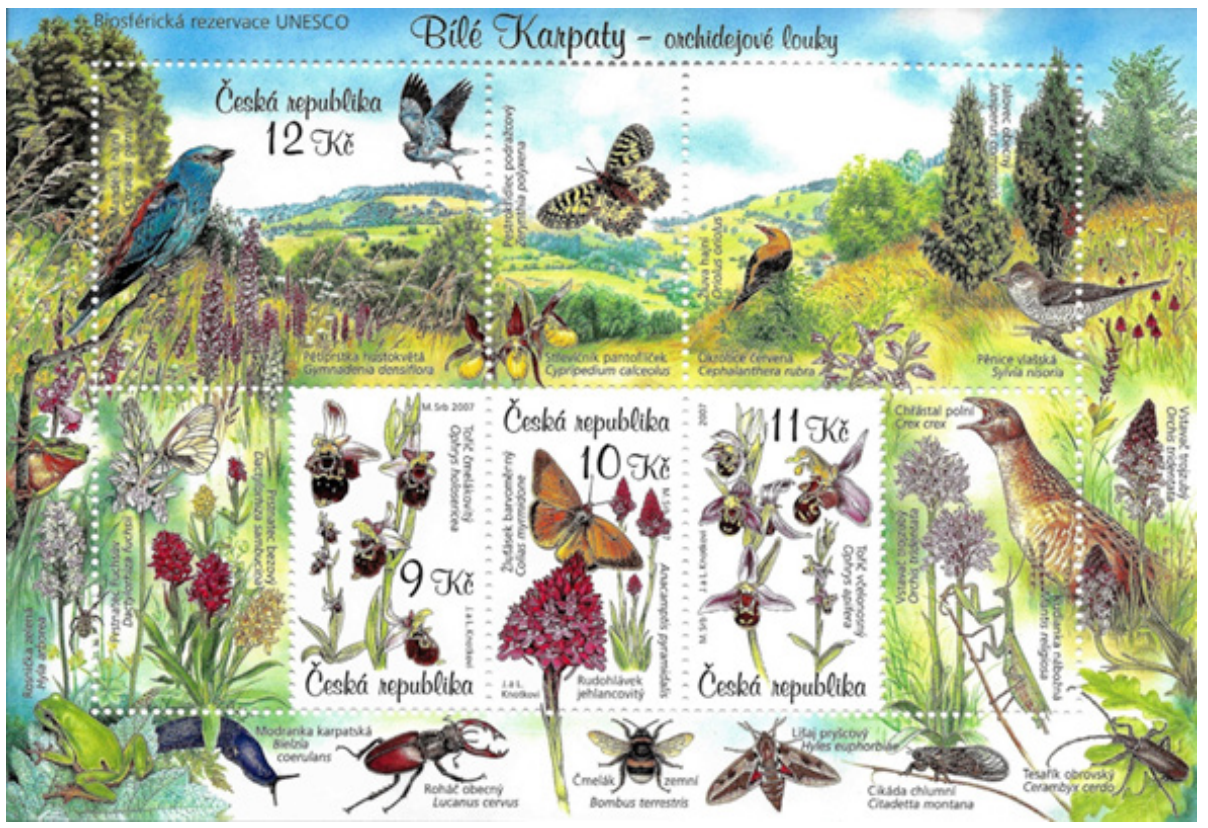

Figura 3. La clase Insecta como parte de la Biodiversidad (República Checa)

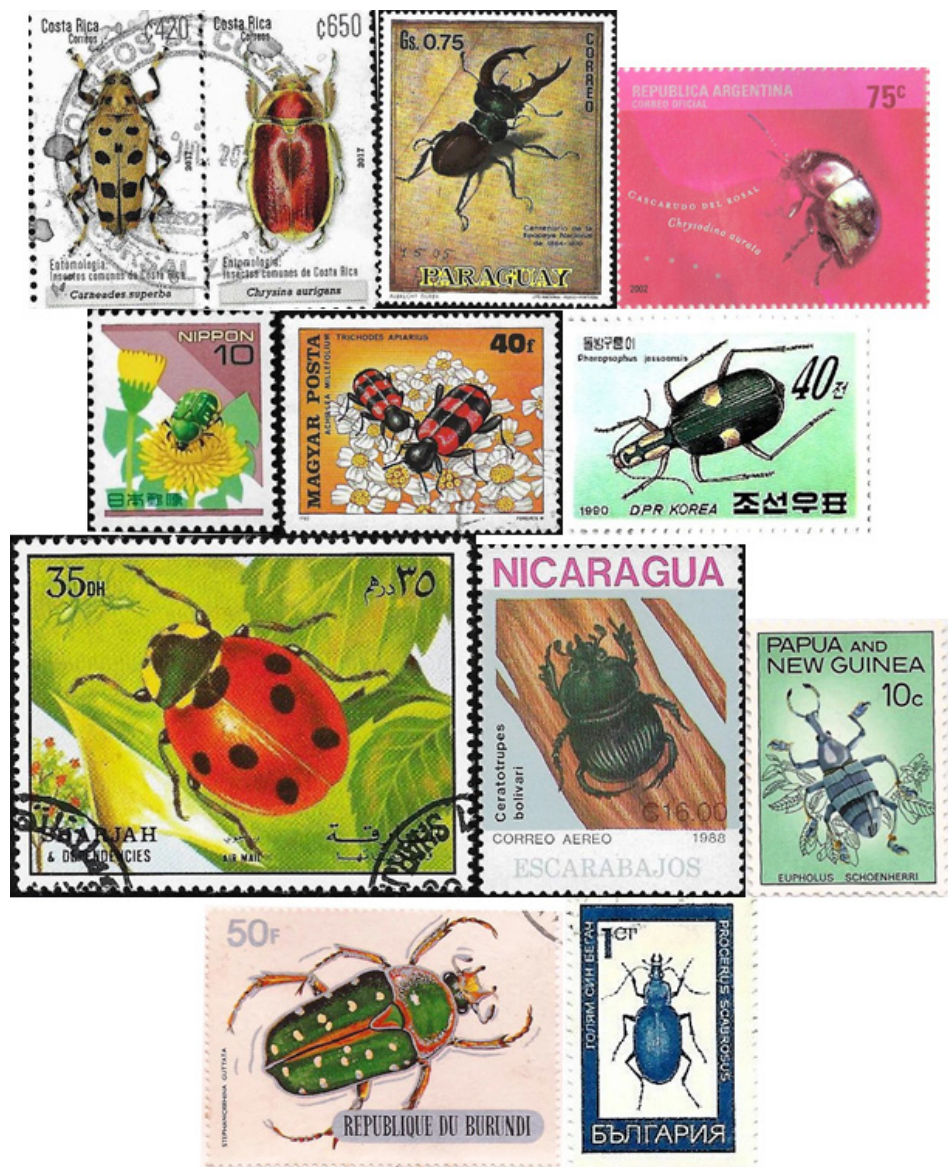

Figura 4. Diversidad de Orden Coleoptera. 


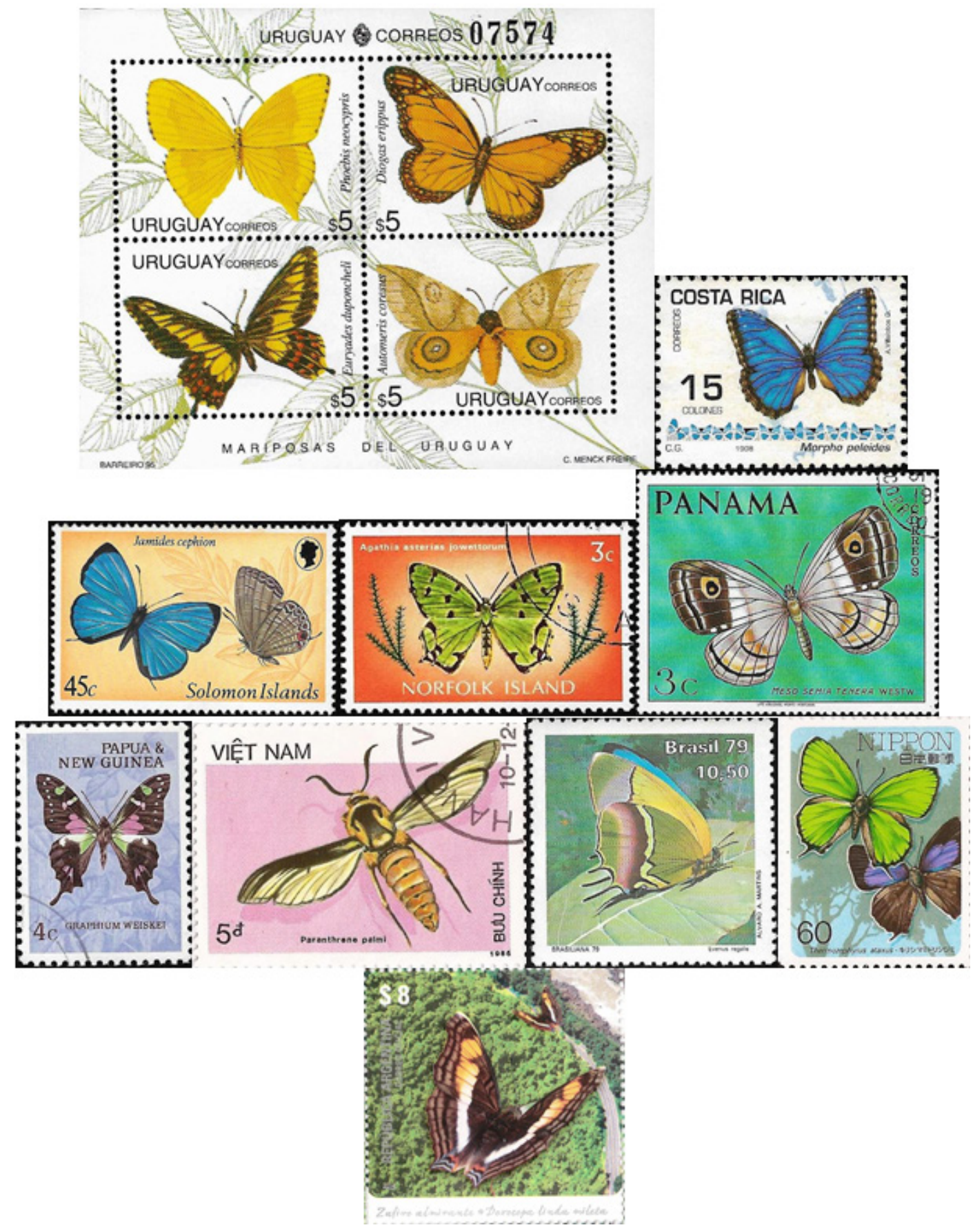

Figura 5. Representantes del orden Lepidoptera. 

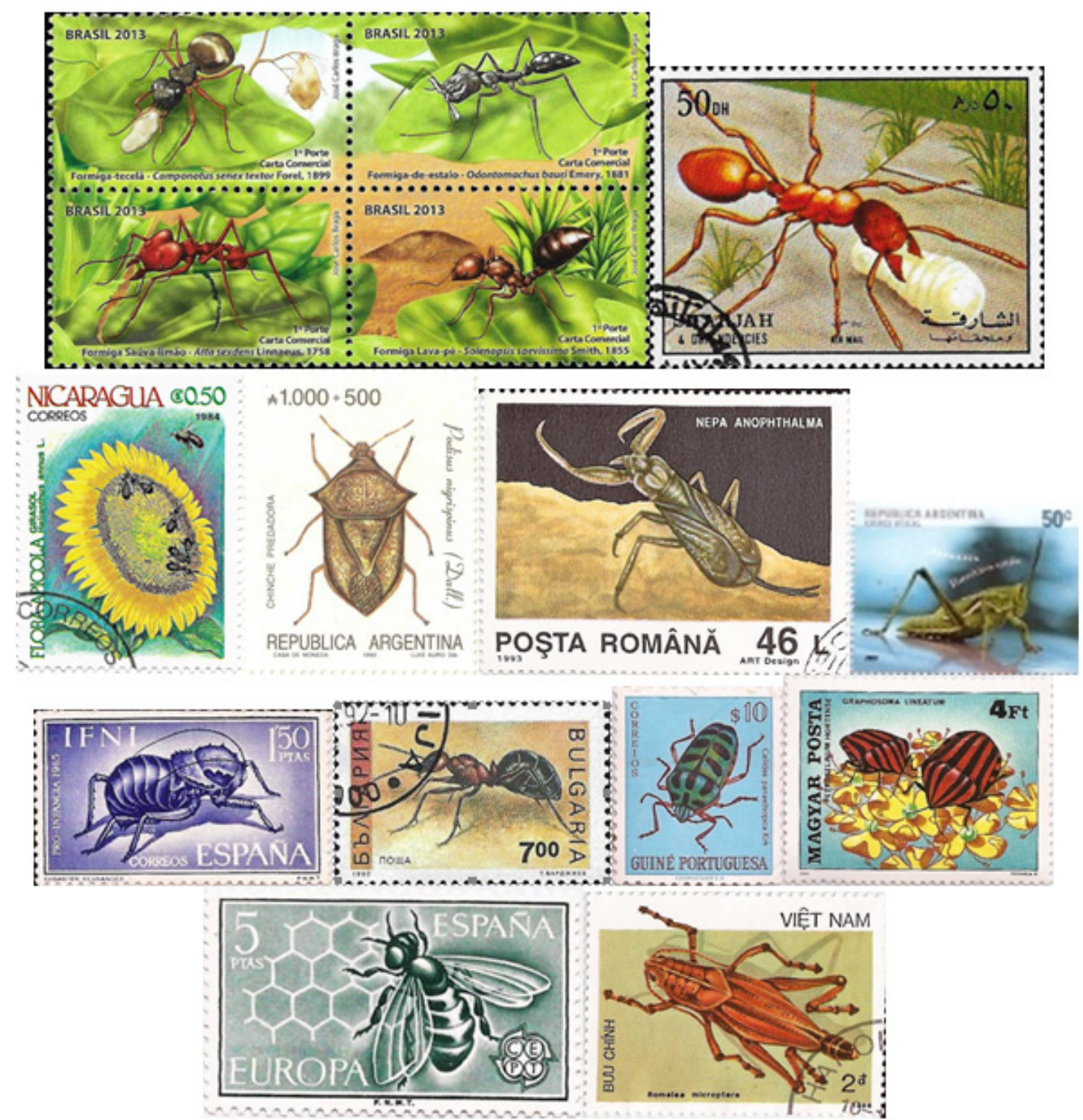

Figura 6. Integrantes de Hymenoptera, Hemiptera y Orthoptera. 


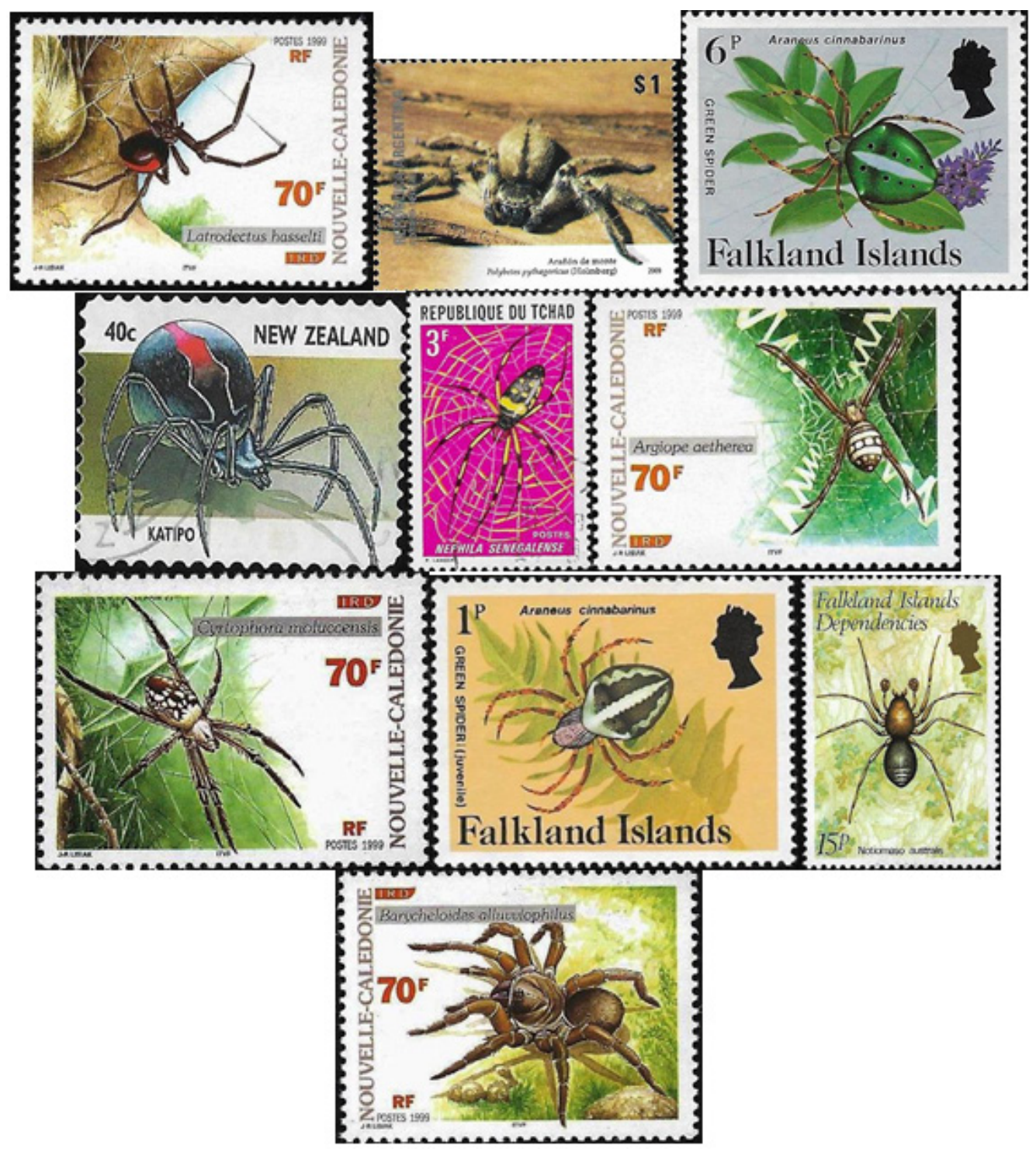

Figura 7. Algunas Araneae presente en esta colección

Tabla 1.Comparación de proporción de ordenes de insectos en estampillas

\begin{tabular}{|c|c|c|}
\hline & Modificado de Mendoza et al., 2006 & Esta colección \\
\hline Lepidoptera & $3173 \quad(68,3 \%)$ & $283(56,7 \%)$ \\
\hline Coleoptera & $452 \quad(9,7 \%)$ & $99(19,8 \%)$ \\
\hline Diptera & $421 \quad(9,1 \%)$ & $24(4,8 \%)$ \\
\hline Hymenoptera & $(6 \%)$ & $37(7,4 \%)$ \\
\hline Orthoptera & $126 \quad(2,7 \%)$ & $14 \quad(2,8 \%)$ \\
\hline Ephemeroptera y Odonata & $109[\mathrm{a}](2,3 \%)$ & $11(2,2 \%)$ \\
\hline Hemiptera & $85 \quad(1,8 \%)$ & $25 \quad(5 \%)$ \\
\hline Otros & & $1,30 \%$ \\
\hline [a] Solo Odonata & & \\
\hline
\end{tabular}

Entre paréntesis ( ), porcentaje correspondiente al total de cada trabajo. 
Se castellanizan la mayoría de los países, especialmente los que presentan alfabetos cirílicos.

En ambas gráficas hay un alto componente de sellos, tanto en bloques como de manera individual, pero no así por su diversidad de especies (Ocampo, 2012) Figura 1 y 2. de sellos de la República Argentina por cantidad

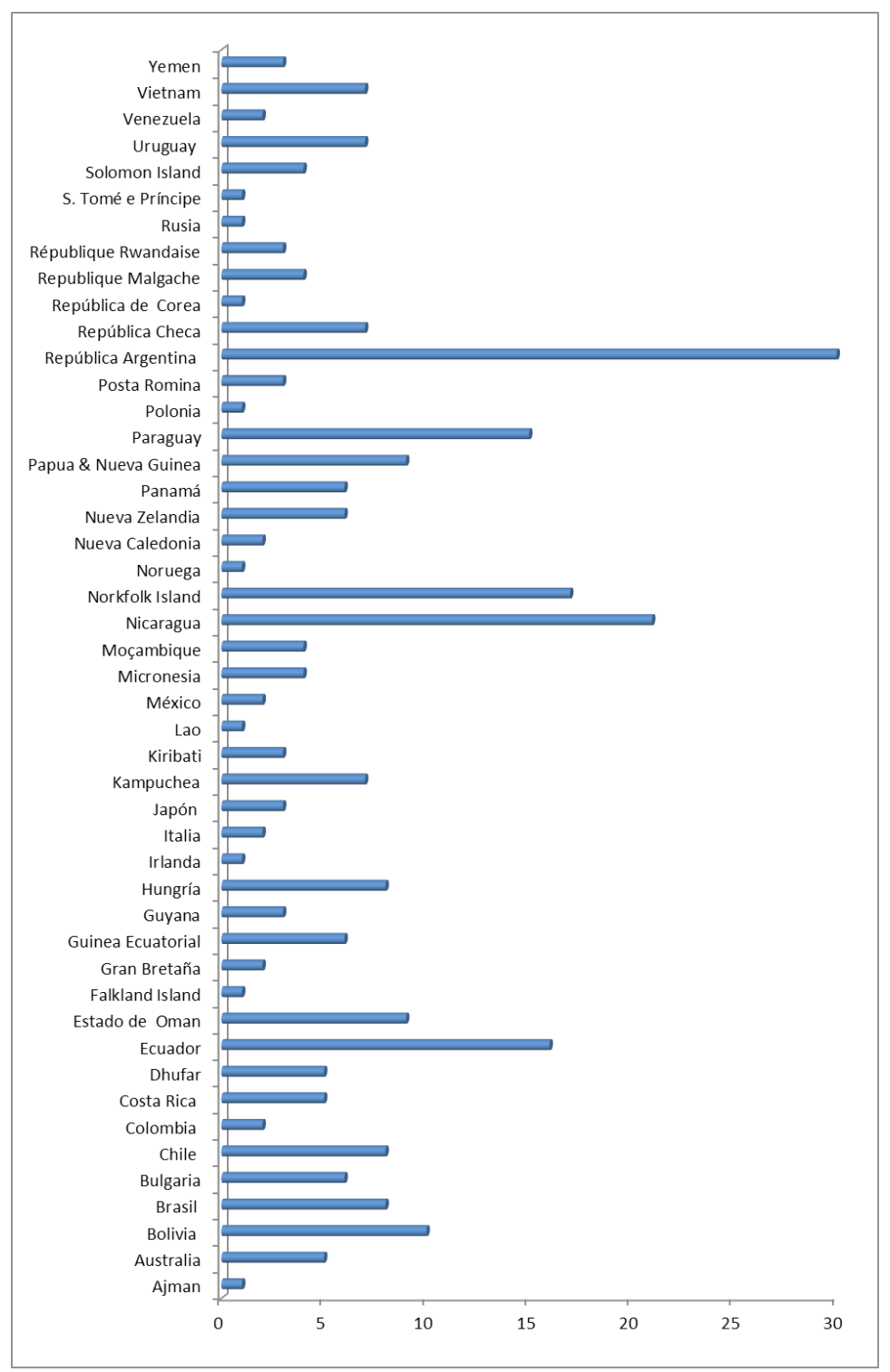

Figura 1: Representación por países de Lepidoptera. 


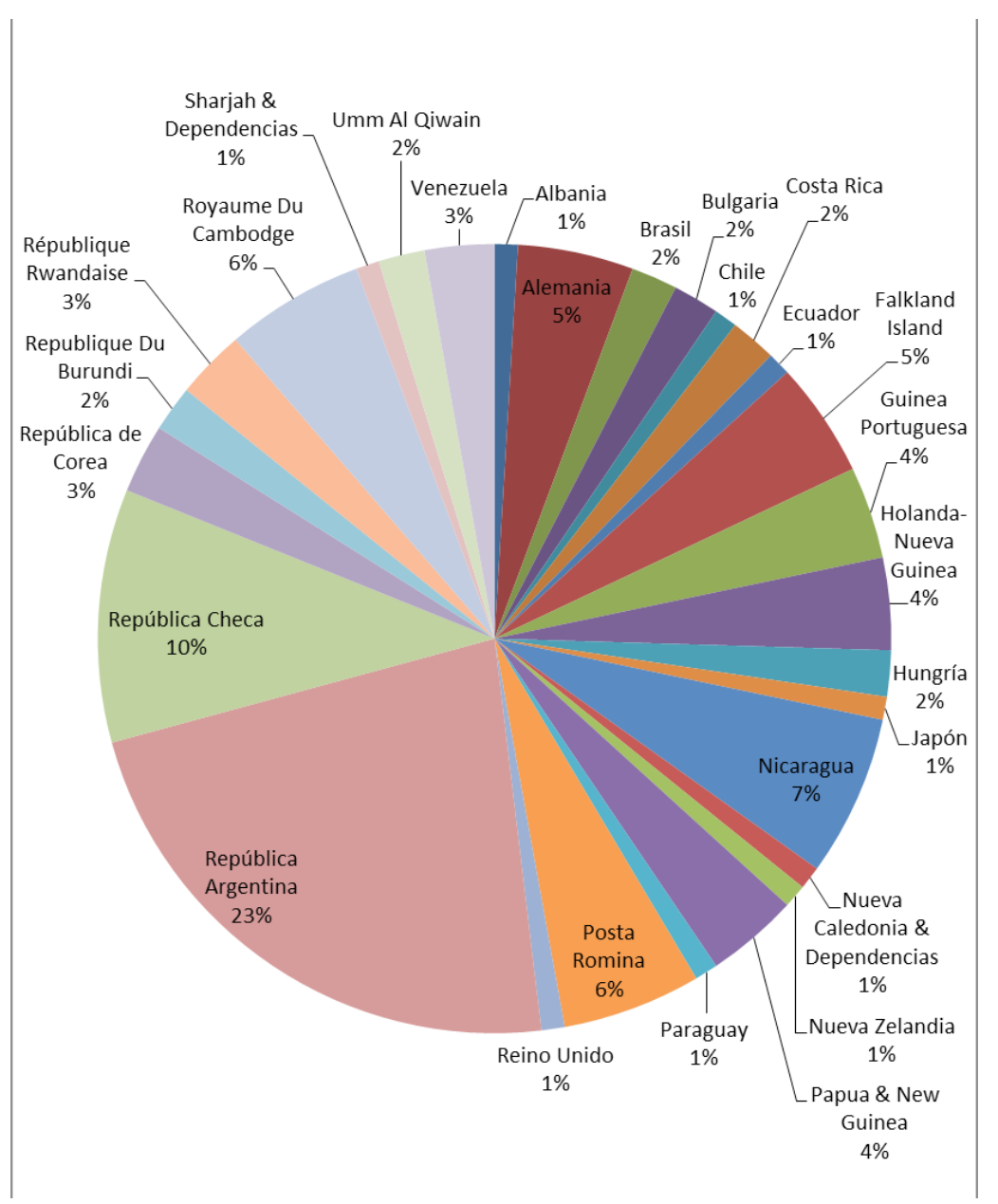

Figura 2: Representación porcentual de Coleoptera.

Respecto de esta colección, Nicaragua es el país mejor representado, particularmente en lo que a Lepidoptera se refiere. Las Islas Malvinas (Falkland Island Dependencies) se ven bien representadas a nivel de riqueza de especies, dada su relativa baja diversidad. Los Lepidoptera se hallan en número interesante particularmente en América, mientras que los Coleoptera están representados en varios países de Europa. Los Hymenoptera son ricos en Nicaragua, Brasil y España.

El uso de material filatélico con fines pedagógicos es la combinación de un arte y un interés profesional, traducido en una herramienta educativa que se puede enfocar a diferentes disciplinas del conocimiento (Martínez-Reina \& Amado-González, 2013, 2016). Es por ello que se pueden abrir varios estudios de líneas de trabajo (Turienzo \& Alves Carneiro, 2017). Cabe destacar que si se cuenta con una colección temática, a su vez se cuenta con apoyo bibliográfico y de referencia por parte del coleccionista que brinda los scanneos de los sellos con fines didácticos. Se recomienda trabajar con scanneos, por lo delicada que es una colección de sellos. Además, los estudiantes podrán acudir a dichas imágenes las veces que lo requieran.

En el caso particular de la entomología, a niveles terciarios y universitarios, se propone seguir el esquema planteado por Pimienta Prieto (2012) (citado por Chávez de Obando et al., 2015) para un marco de referencia pedagógico-didáctico. Respecto de los contenidos, se puede profundizar en temas como sistemática y catálogos de especies, biogeografía, paleontología y linajes evolutivos. Aquí, se pueden confeccionar fichas de ejemplares a nivel individual de especie, detallando características morfológicas diferenciales del ejemplar, su posición 
sistemática, su nicho desde lo ecológico y geográfico, su distribución y hábitats, sus hábitos alimenticios, su reproducción y otros comentarios de interés (como genéticos, fisiológicos, del registro fósil, etc) con sus respectivas citas bibliográficas. Ejemplos de ello pueden consultarse tanto en insectos (Turienzo, 2018a) como en vertebrados (Turienzo \& Zervos, 2018, Turienzo, 2018b)

Hay familias muy bien representadas en los sellos postales como las Carabidae (Turienzo \& Alves Carneiro, 2014) y los Scarabaeidae (Gómez y Gómez \& Junghans, 2002). A su vez, el grupo de los Lepidoptera es el mejor representado a nivel mundial (para poder indagar en él ver \% en la colección que se menciona, Costa Neto, 2002, Mendoza Ramírez et al., 2006, Reyes \& Núñez Águila, 2008, PalaciosVargas \& Navarrete-Heredia, 2003). Varios grupos no han sido incluídos aún en los timbres postales, tales como los Embioptera, Siphonaptera, Thysanoptera y Anoplura (Palacios-Vargas, 2011). Otros grupos, que no son tan significativos a nivel cantidad de especies, pero sí a nivel sanitario como las "cucarachas" (Blattodea), también se representan en la filatelia tan solo con 8 sellos (Gómez et al., 2015).

En carreras donde la entomología está incorporada en la futura práctica diaria en diagnosis, como veterinaria, medicina y/o agronomía, forestal y carreras afines, este tipo de recursos podría afirmar visualmente grupos con los que podrán encontrarse a diario. En estos casos se podría vincular los insectos con sus hospedantes en una red conceptual, tal como se emplean en la enseñanza de la química (MartínezReina \& Amado-González. 2016).

Dado que en algunos diseños curriculares también son incluidos los arácnidos con interés sanitario (básicamente por su importancia como animales venenosos) y eventualmente otros artrópodos de interés veterinario, solo se hará mención de trabajos relacionados con estos grupos a nivel taxonómicos tales como Gómez \& Junghans (2016) para Scorpionida, Araneidae, Scorpionida y Acari (Maury, 1998) y los Acarida (Palacios-Vargas \& Navarrete-Heredia, 2003, Palacios-Vargas, 2011).

En este trabajo, se ilustra el orden Araneae de esta colección (que no se hallan incluidos junto a los datos de Insecta), a título de ilustrar sellos nuevos que complementan en parte el trabajo de Maury (1998).

Respecto de la enseñanza de la entomología mediante esta modalidad didáctica (al conocimiento a la fecha), es el primer trabajo del que se tiene conocimiento por parte de la autora.
En los últimos años se han realizado en la Argentina otro tipo de trabajos con sellos postales, con intención de divulgar aspectos más concretos dentro de disciplinas como la ornitología (Turienzo \& Rodríguez Molina, 2014), entomología (Ocampo, 2012; Turienzo \& Alves Carneiro, 2014, 2015) y paleontología (López, 1998), mastozoología/ espeleología (Lipps, 2008, Turienzo \& Zervos, 2018, en prensa, Turienzo, 2018) y en el estudio de peces (Salazar \& Turienzo, 2018b).

De allí la necesidad de generar material con diversas ópticas a analizar en el campo de las ciencias naturales.

En general, los temas presentes en los sellos postales que contienen imágenes de insectos destacan los siguientes aspectos: taxonomía, distribución geográfica, importancia médica, veterinaria, agrícola, cultural, apicultura y fauna local (Costa Neto, 2002, PalaciosVargas \& Navarrete-Heredia, 2003) y otros artrópodos como los de la Clase Arachnida, Clase Crustácea y Clase Acarida (Maury, 1998, Palacios-Vargas \& Navarrete-Heredia, 2003, Gómez \& Junghans, 2016). Para la enseñanza y aprendizaje se pueden utilizar dispositivos auxiliares como datashow, fotografía, internet, etc., para trabajar con estos sellos (Penereiro \& Lombardo Ferreira, 2010). Este tipo de herramientas se pueden utilizar con los insectos en los sellos como tema transversal, dado que el uso de los sellos postales permite un análisis profundo a nivel iconográfico, ya que las imágenes están diseñadas por artistas (fotógrafos, artistas plásticos, etc.). De esa manera el estudiante puede fijar la imagen para su reconocimiento (por ejemplo en caso de ejemplares venenosos), sin necesidad de utilizar colecciones con fines científicos de material complejo de conseguir o complicado de colectar, como es el caso de los artrópodos venenosos (ej., para futuros médicos, veterinarios, etc).

Se considera que los sellos son importantes desde el punto de vista didáctico, tomando en cuenta los comentarios de los autores que siguen:

"Una de las causas (por la que no prospera la filatelia en varios países de América) es que no se tiene cultura de coleccionar, solo de "amontonar", ya que el coleccionismo se define como la actividad de estudiar, analizar y conceptualizar un conjunto de objetos para ordenarlos sistemáticamente". (Mendoza Ramírez et al., 2006).

"Los sellos pueden ser mucho más que los meros comprobantes de tarifas pagas por servicios postales, constituyendo una importante fuente de información sobre aspectos socioculturales, históricos, científicos y económicos de los países 
emisores, así como de sus riquezas naturales". (Welker, 2010.Traducido del portugués).

Tal como plantea Abad: "Desde el punto de vista de la enseñanza, la filatelia es una actividad educativa y transmisora permanente de valores culturales dado su carácter interdisciplinar; estimula la creatividad y permite explorar temas curriculares de una manera diferente (...). Plantear a la filatelia como un entretenimiento que alienta a investigar, leer, realizar consultas, intercambiar material para saber sobre el tema elegido. Con la filatelia fomentamos el aprendizaje activo y productivo en un marco intergenaracional y a nivel mundial. Un sello puede ser el punto de encuentro de lugares y culturas, del que podemos aprender y con el que se puede llevar a cabo el proceso de enseñanza aprendizaje". (Abad, 2014).

Coincido con Gómez y Gómez, B. \& C. Junghans. (2002), en que la educación es la base para la toma de conciencia y para el cambio de conductas a nivel individual y comunitario (autores que, a su vez, reconocen a la filatelia como educativa desde la problemática de la crisis de biodiversidad, y su aprendizaje a través de ella).

\section{Conclusiones}

Por otra parte, como docentes nos enfrentamos con la necesidad de implementar nuevas estrategias, para motivar el aprendizaje en nuestros estudiantes, tanto en el desarrollo de competencias en el área metodológica como con la incorporación de contenidos teóricos.

El empleo de innovaciones metodológicas para una buena didáctica de la ciencia, tal como la que se presenta, complementa la formación desde el campo constructivista-cognitivista mediante la investigación deactividadesqueplanteenunaprendizajesignificativo. Además, dada la existencia de inteligencias múltiples, la utilización de representaciones visuales, en este caso desde lo iconográfico sería útil para integrar con temas transversales como las exportaciones, pandemias, etc., re-interpretando los saberes que el alumnado trae consigo.

Es una propuesta que, si bien es aplicada a la entomología, pretende trascender a una interdisciplina.

\section{Agradecimientos}

A Walter Alves Carneiro (Necochea, Buenos Aires), por su constante apoyo (y por iniciarme en este maravilloso arte), como también por los sellos que he obtenido como regalo. A Diego Funes (San Rafael, Mendoza) y Claudio Domínguez (Godoy Cruz, Mendoza) por estar siempre atentos a sellos para mi colección.

\section{Literatura citada}

Abad, M.E.

2014. El valor educativo de la filatelia. Disponible en: http://www.lavozdegalicia.es/noticia/firmas/2014/09/13/ valor-educativo-filatelia/0003_201409º13C12992.htm. Consultado: 01/ ju1/2017.

Chávez de Obando, M.; Rojas J., J. del C.; Sánchez, R.

2015. Internalización de la formación en la Educación Superior. La filatelia como estrategia de enseñanza en la Historia La Red CESAL. Panamá-Costa Rica. 9 p.

Correos De Chile.

2013. Doscientos sesenta años del correo en Chile. Correos de Chile. Santiago, Chile. 197p.

Costa Neto, E.M.

2002. Entomofilatelia: Os insectos na arte filatélica. Bioikos, 16 (1/2): 61-67.

Gómez y Gómez, B.; Junghans, C.

2002. Los Scaraboideae (Insecta: Coleoptera) en la filatelia. Cuadernos de biodiversidad, 11 (año IV): 10-14.

Gómez, B.; Junghans, C.

2016. Los alacranes (Arachnida: Scorpionida) en la filatelia Dugesiana, 23 (1): 37-43.
Gómez, B.; Domínguez, M. R.; Junghans, C.

2015. Las cucarachas (Blattodea) representadas en los sellos postales (entomofilatelia). En: Castaño-Meneses, G. \& J.L. Navarrete-Heredia (coords.) Avances en la Entomología Cultural Mexicana UNAM-CUCB: Universidad de Guadalajara. Guadalajara, México. Pp: 77-82.

Lipps, E.

2008. Los murciélagos y la filatelia. Sociedad Argentina de Espeleología. Bs. Ar., Argentina. 5 p.

López, M.G.

1998. El Museo de La Plata, la paleontología Argentina y sellos postales. Revista Museo, 12: 31-36.

Madero, C.; Marquehoss, G.; rodríguez, L.; Simó, M.

2013. Biofilatelia: Los seres vivos en la filatelia uruguaya. Boletín de la Sociedad Zoológica del Uruguay, 22 (2): 10-15.

Martínez-Reina, M.; Amado-González, E.

2013. Historia y didáctica de la química a través de sellos postales: Un ejemplo con Marie Curie. Educ. quím., 24 (1): 71-78 
Martínez-Reina, M.; Amado-González, E.

2016. Filatelia y didáctica de la química: un ejemplo con los gases ideales. Rev. Cubana Quím., 28 (3): 843-869.

Maury, E.A.

1998. Arácnidos y Filatelia. Revista Museo, 11: 69-73.

Mendoza Ramírez, M.; Pacheco Rueda, I., Sarmiento Cordero,

M.A.; Zurita García, M.L.

2006. Entomofilatelia en México: tributo a la amistad de los insectos. Sociedad Entomológica Aragonesa, 38: 443-449.

Ocampo, F.C.

2012. Estampillas Entomológicas Argentinas. Boletín SEA, 23 (1): 8-9.

Palacios-Vargas, J.G.; Navarrete-Heredia, J.L.

2003. Entomofilatelia, un aspecto de la Entomología cultural. En: Biodiversidad, taxonomía y biogeografía de artrópodos de México: Hacia una síntesis de su conocimiento. Vol. III. CONABIO-UNAM. Pp: 107-115.

Palacios-Vargas, J.G.

2011. Entomofilatelia: Las estampillas postales con insectos y otros artrópodos en el mundo. En: Navarrete-Heredia, J.L., G. Castaño Meneses \& G.A. Quiroz-Rocha (Eds.). Facetas de la Ciencia: Ensayos sobre Entomología Cultural. Universidad de Guadalajara. Pp: 15-16.

Penereiro, J.C.

1997. A filatelia como forma de divulgação da astronomía. Caderno Catarinense de Ensino de Física, 14 (1): 64-82.

Penereiro, J.C.; Lombardo Ferreira, D.H.

2010. Matemática na arte filatélica: Um olhar histórico da matemática por meio de imagems em selos postais. REnCiMa, 1 (2): 126-144.

Penereiro, J.C.; Lombardo Ferreira, D.H.

2011. Filatelia como mecanismo de divulgação e de ensino as engenharias no Brasil. R.B.E.C.T., 4 (2): 84-104.

Salazar, L.V.; Turienzo, P.

2018. Filatelia mundial de peces como recurso didáctico en el nivel terciario. 2do Congreso Nacional en Enseñanza de las Ciencias Naturalesm Matemática y Educación Inclusiva e Intercultural (Resumen extendido). 11 p.
Reyes, E.; Núñez Águila, R.

2008. La Entomología en la Filatelia Cubana. Sociedad Entomológica Aragonesa, 43: 459-462.

Turienzo, P.

2018a. Bioespeleofilatelia: Clivina subterranea (Coleoptera: Carabidae). EspeleoAr, 18: 15-16.

Turienzo, $\mathrm{P}$.

2018b. Chiroptera (murciélagos) en los sellos postales de Uruguay. Gota a Gota, 16: 34-36.

Turienzo, P.; Alves Carneiro, W.

2014. Los insectos de la familia Carabidae (Ground Beetles) en la filatelia mundial. Biologica, 17: 77-78.

Turienzo, P.; Alves Carneiro, W.

2015. Los coleópteros en la filatelia de América. Boletín Drosophila, 17: 14-16.

Turienzo, P.; Alves Carneiro, W.

2017. La enseñanza de la biodiversidad por medio de la filatelia: El caso de la Argentina. I Congreso Provincial de Enseñanza de las Ciencias Naturales (Resumen). 6 p.

Turienzo, P.; Rodríguez Molina, M.

2014. Las aves en la filatelia mundial. El caso puntual de la familia Spheniscidae Bonaparte, 1831 (Spheniciformes). Biologica, 17: 36-39.

Turienzo, P.; Salazar, L.V.

2018. La enseñanza e la Biodiversidad por medio de la Filatelia. Taller en el marco del 2do Congreso Nacional en Enseñanza de las Ciencias Naturalesm Matemática y Educación Inclusiva e Intercultural (Resumen extendido). 5 p.

Turienzo, P.; Zervos, N.

2018. Biodiversidad Argentina: Los Quiróptera (murciélagos) plasmados en los sellos postales. Gota a gota, 16: 27-29.

Turienzo, P.; Zervos, N.

2018. El orden Chiroptera (murciélagos) en la filatelia de América. Resumen extendido en número especial de EspeleoAr, Boletín Electrónico de la Unión Argentina de Espeleología.

Welker, C.A.D.

2010. A filatelia como forma de divulgação da flora brasileira. Revista Brasileira de Biociências, 8 (3): 273-278. 
